\title{
A Patient with Obstructive Sleep Apnea Syndrome Presenting with REM Sleep Behavior Disorder Mimicking Symptoms
}

\author{
Eun Hye Oh, Dae Jin Kim, Ki Tae Kim, Seung-Joo Kim, Kyung Ha Noh, Jae-Wook Cho \\ Department of Neurology, Pusan National University Yangsan Hospital, Pusan National University School of Medicine, Busan, Korea
}

\begin{abstract}
렘수면행동장애 유사 증상을 보인 폐쇄수면무호흡증후군 환자
\end{abstract}
오은혜, 김대진, 김기태, 김승주, 노경하, 조재욱

부산대학교 의학전문대학원 양산부산대학교병원 신경과학교실

\author{
Received December 7, 2014 \\ Revised December 15, 2014 \\ Accepted December 23, 2014 \\ Address for correspondence \\ Jae-Wook Cho, MD \\ Department of Neurology, \\ Pusan National University \\ Yangsan Hospital, Pusan National \\ University School of Medicine, \\ 20 Geumo-ro, Mulgeum-eup, \\ Yangsan 626-770, Korea \\ Tel: +82-55-360-3014 \\ Fax: +82-55-360-2152 \\ E-mail: sleep.cho@gmail.com
}

\begin{abstract}
Rapid eye movement (REM) sleep behavior disorder (RBD) is characterized by dream-enacting behaviors during REM sleep. However, many sleep disorders can produce RBD mimicking symptoms, also known as 'pseudo-RBD'. We report a patient with severe obstructive sleep apnea with 'pseudo-RBD' symptoms that were eliminated by continuous positive airway pressure treatment. Polysomnography is mandatory to establish the proper diagnosis of RBD.
\end{abstract}

J Korean Sleep Res Soc 2014;11(2):72-75

Key Words: REM sleep behavior disorder, Obstructive sleep apnea, Continuous positive airway pressure.
렘수면행동장애(REM sleep behavior disorder, RBD)는 사 건 수면의 하나로, 렘수면(rapid eye movement sleep, REM sleep) 중 나타나야 하는 근육이완의 소실 때문에 렘수면 도 중 꿈을 꿀 때 그 내용대로 행동하는 수면 질환이다. 심할 경 우 꿈 내용대로 행동하다가 벽을 치거나 같이 자는 사람을 때 리기도 하기 때문에 외상, 출혈 등을 초래할 수 있다. 렘수면 행동장애를 시사하는 병력이 있으면 수면다원검사를 시행하 여 그 행동을 직접 확인하거나, 검사 당일 행동을 관찰할 수 없어도 렘수면에서 턱근긴장의 증가(REM atonia dissociation)의 유무를 확인하여 진단하게 된다. 그러나 수면 중 RBD 와 유사한 행동을 보이는 경우가 드물게 존재하는데, 이러한 유사 증상을 가성렘수면행동장애(pseudo-RBD)라고 부르기 도 한다. ${ }^{1}$

저자들은 꿈 내용대로 행동하는 증상 때문에 렘수면행동

This is an Open Access article distributed under the terms of the Creative Commons Attribution Non-Commercial License (http://creativecommons.org/licenses/by-nc/3.0) which permits unrestricted non-commercial use, distribution, and reproduction in any medium, provided the original work is properly cited.
장애로 오인할 수 있었던 심한 폐쇄수면무호흡증을 진단하 고, 지속기도양압을 시도하여 증상이 사라진 환자를 경험하 여 보고한다.

\section{증 례}

35세 남자가 잠을 잘 때 꿈처럼 행동하고 다리를 매우 심 하게 떤다고 병원에 왔다. 꿈처럼 행동하는 증상은 3 4년 전 부터 거의 매일 있었으나 벌떡 일어나거나 침대 밖으로 뛰어 나가는 큰 행동이 없어, 병원에서 진료 받은 적은 없었다. 다 리를 떠는 증상은 1년 전 척추미세침 치료 후 발생한 S1 신경 뿌리병 이후 발생하였다고 한다. 증상은 매일 있었고, 코골이 도 심하다고 하였다. 낮에 매우 졸렸고 Epworth Sleepiness Scale 점수가 22점이었다. 다른 내과 질환은 없었고, 이학적 및 신경학적 검사는 정상이었다. 신체체질량지수가 38.2로 심한 비만이었다.

야간 수면다원검사를 시행하였는데 무호흡-저호흡지수 
(apnea hypopnea index)가 $131.8 / \mathrm{hr}$ 로 매우 높게 측정되었 으며 심한 코골이도 동반되었다. 무호흡이 발생할 때 최저 산 소포화도는 59\%였다. 수면 잠복기가 4.0분으로 짧아져 있었 고 입면 후 각성은 42.9분으로 전체 수면의 $16.3 \%$ 였으며, 수 면효율은 $82.3 \%$ 로 감소하였다. 각성지수도 $97.3 / \mathrm{hr}$ 로 상당 히 증가하였다. 수면구조는 얕은 잠이 거의 대부분으로, N1 수면이 $84.2 \%$ 로 증가하고 N2 수면은 2.8\%로 감소하였으며 $\mathrm{N} 3$ 수면은 없었다. 꿈을 꾸는 듯한 행동은 렘수면에서 2회, 비렘수면에서 2회로 총 4회 나타났는데(Fig. 1), 각성이 일어 나도 수면 단계가 바뀌지는 않았지만 움직이는 동안 턱근전 도의 진폭은 증가하였다. 행동 양상은 알아듣지 못하는 소리 로 중얼거리면서 휴대폰으로 통화하는 동작을 취하기도 하 고, 담배 피우는 시늉을 하거나 문을 여는 행동, 양손을 닦는 동작을 보이기도 하였다. 그러나 발길질이나 욕설 등 폭력적 인 행동은 없었다. 이러한 행동의 시작은 모두 심한 폐쇄수면 무호흡과 연관된 각성 직후부터 시작되었고 15 초에서 30 초 가량 지속되었다. 증상이 있는 기간 동안 턱근전도의 진폭이 다소 증가하였는데, 특히 증상 시작 시 3 4초 동안 뚜렷하게 증가하는 양상이었다. 수면 기간의 $13 \%$ 에 해당하는 렘수면 동안에는 턱근전도 진폭의 증가는 없었으나, 심한 주기사지 운동장애가 잠을 자는 동안 1 2초에 1회의 빈도로 매우 잦아 횟수를 셀 수 없을 정도였다.

매우 심한 폐쇄수면무호흡과 코골이를 확인하여 수면다원
검사 후반부에 지속기도양압 적정검사를 시작하였다. 무호 흡과 코골이가 없어질 때까지 압력을 올린 결과, 압력 $14 \mathrm{~cm}$ $\mathrm{H}_{2} \mathrm{O}$ 에서 무호흡-저호흡 지수가 $16.3 / \mathrm{hr}$ 로 감소하였고 각성 지수도 $8.5 / \mathrm{hr}$ 로 많이 줄었다. 각성지수가 감소하면서 렘수 면과 N3 수면이 늘어났으며(Fig. 1), 간헐적으로 보이던 꿈 꿀 때 취하는 행동도 사라졌다. 렘수면 시 턱근긴장도의 변화는 관찰되지 않았다. 다리의 움직임 횟수는 지속기도양압 치료 전과 비교해 줄지 않았으나 그 움직임으로 인해 각성이 유발 되지는 않았다. 지속기도양압 치료의 필요성을 설명하였으나 환자가 사용하기를 거부하여 이후 추적관찰은 불가능하였다.

\section{고 찰}

본 증례는 수면 시 나타나는 이상행동에 대한 평가를 위해 수면다원검사를 시행하고, 폐쇄수면무호흡 후 발생한 이상 행동으로 진단하여 지속기도양압으로 무호흡을 감소시킨 증 례다. 수면 중 꿈과 연관된, 주로 폭력적인 양상의 행동을 보 여서 병력상 렘수면행동장애와 비슷한 양상을 보이는 가성 렘수면행동장애에 속하는 질환은 여러 가지가 있다. 몽유병, 야경증과 같은 사건 수면 외에도 야간발작, 간헐적 야간이동 (episodic nocturnal wandering), 비렘수면과 렘수면의 율동운 동질환, 야간 정신성 해리장애, 꾀병, 그리고 폐쇄수면무호흡 증 등의 질환들이 유사하다. ${ }^{1}$

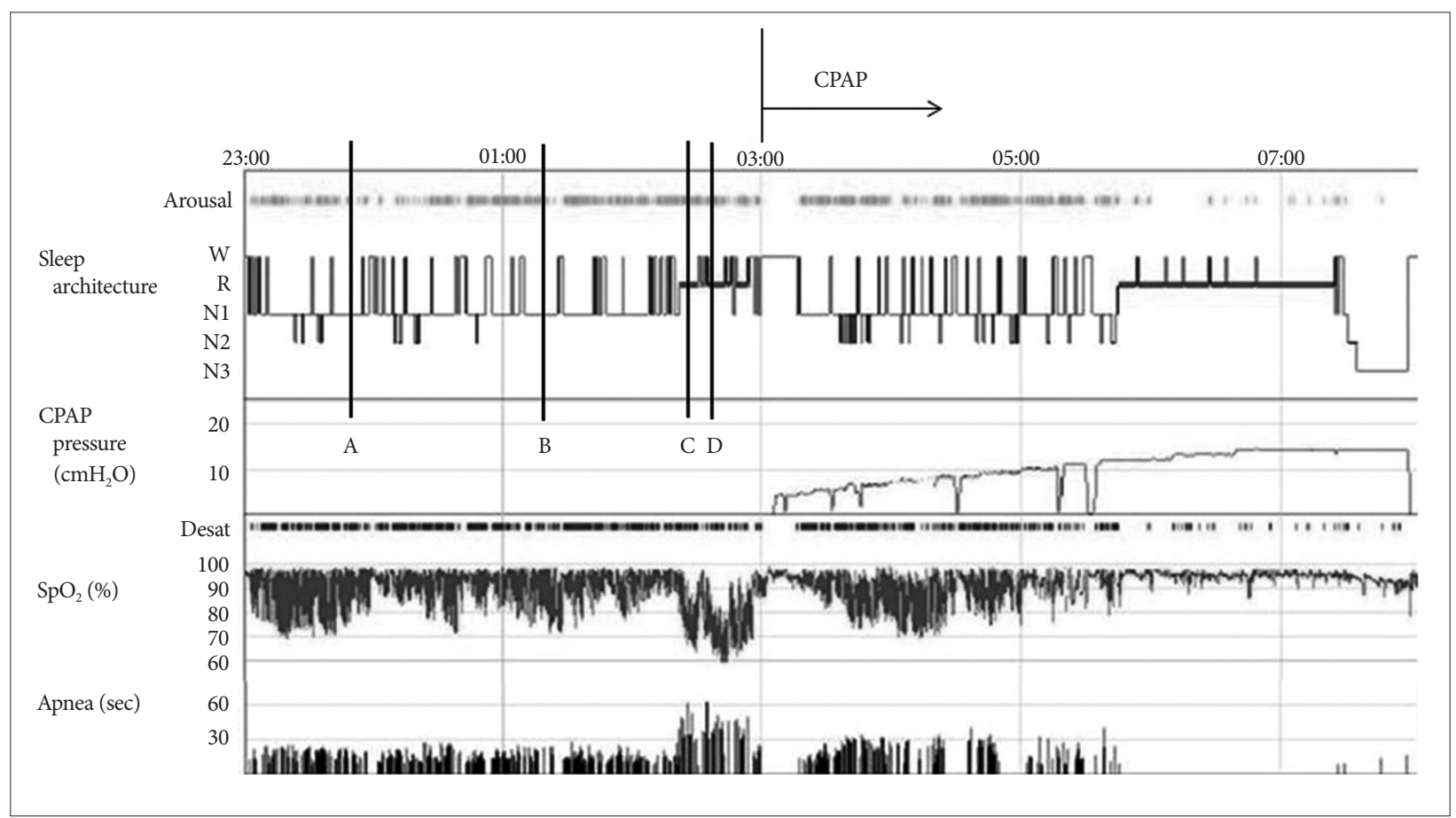

Figure 1. Night polysomnography. It demonstrates frequent arousals due to apnea and hyponea. Vertical bars indicate REM sleep behavior disorder mimicking events occurrence. Two episodes (bar A, B) occurred during N1 sleep, and the others (bar C, D) occurred during REM sleep. $\mathrm{SpO}_{2}: \mathrm{O}_{2}$ saturation, CPAP: continuous positive airway pressure, sec: second. 
이러한 가성렘수면행동장애 중 폐쇄수면무호흡증 환자의 증례는 국외에서 아주 드물게 보고되었고 대규모의 임상연 구가 아직 없어서 정확한 발병기전이나 유발요인, 임상적 특 징 등에 대해서는 잘 알려져 있지 않다. ${ }^{2}$ 기존에 보고된 증례 들이 모두 무호흡 혹은 저호흡과 연관된 각성 단계에서 주로 증상이 나타났기 때문에 혼돈각성의 한 형태가 아닐까 추측 되고, 23 무호흡-저호흡 지수가 높고 산소포화도가 심하게 감 소하는 중증의 폐쇄수면무호흡증 환자에게 잘 나타나리라 사료된다. ${ }^{4}$ 그러나 모든 중증 폐쇄수면무호흡 환자가 비슷한 증상을 보이는 것은 아니며 미세각성이 잦은 다른 수면장애 에서 흔하게 관찰되는 증상도 아니라는 점에서, 어떤 요소가 이런 증상을 유발하는지는 좀 더 연구가 필요하다.

과거 보고된 폐쇄수면무호흡증의 사례들과 비교했을 때 본 증례는 임상양상과 수면단계에서 차이가 있다. 먼저 임상 양상을 살펴보면 본 예의 동작은 공격적이거나 크지 않았고, 전화통화나 손 닦기, 담배 피우기 등 일상생활에서 흔히 볼 수 있는 동작들이었던 반면, 과거 보고된 증례들은 일반적인 렘수면행동장애 환자들처럼 폭력적이거나 악몽, 쫓기는 꿈 내용과 연관된 행동들이었다. 또한, 이전 증례들은 모두 렘수 면 단계에서 꿈처럼 행동하는 증상이 관찰되었으나, 본 증례 에서는 렘수면 때와 더불어 비렘수면인 N1 수면에서도 증상 이 나타났다. 렘수면 단계에서 근긴장도가 떨어지면서 폐쇄 수면무호흡이 더 잘 생길 수 있고, 이로 인한 각성도 더 빈번 하게 나타나므로 폐쇄수면무호흡증 환자는 렘수면 단계에서 꿈과 연관된 이상행동이 더 자주 관찰될 수 있다고 생각할 수 있다. 그러나 일반적으로 꿈은 $80 \%$ 정도는 렘수면 단계에서, $20 \%$ 는 비렘수면에서 꾸는 것으로 알려져 있으므로, ${ }^{5}$ 본 증례 처럼 비렘수면 단계에서 꿈을 꿀 때 무호흡으로 인한 각성이 발생한다면 이상행동이 충분히 나타날 수 있을 것이다.

렘수면행동장애와 폐쇄수면무호흡증은 둘 다 남성에게서 호발하며 나이가 들수록 유병률이 높아진다. ${ }^{6}$ 하지만 약물치 료가 우선인 렘수면행동장애에 비해 폐쇄수면무호흡증은 지 속기도양압이나 수술적 치료, 구강 내 장치 등이 먼저 고려되 어야 하기 때문에 가성렘수면행동장애 형태의 폐쇄수면무호 흡증과 렘수면행동장애의 감별진단이 필요하다. 또한, 특발 성 렘수면행동장애로 진단받은 환자 중 $80 \%$ 이상이 파킨슨 씨 병이나 치매 등의 퇴행성 뇌질환으로 진행한다는 연구결 과가 있어, 렘수면행동장애의 정확한 진단은 매우 중요하다.? 새로 개정된 국제수면장애분류의 진단 기준(International Classification of Sleep Disorders-third edition)에 따르면 렘 수면행동장애를 진단하기 위해서는 병력상 반복되는 수면관 련 발성이나 이상행동이 존재하고, 이러한 증상이 렘수면 시 기에 발생해야 하며, 수면다원검사를 시행하여 근긴장소실
이 사라진 렘수면 단계가 증명되어야 한다. ${ }^{8}$

렘수면행동장애와 유사한 증상을 보인 폐쇄수면무호흡증 환자 16 명과 렘수면행동장애 환자를 대상으로 한 연구에서, 양쪽 모두 폭력적인 행동을 하거나 악몽을 꾸는 경우가 많아 폐쇄수면무호흡 환자와 RBD 환자의 꿈 내용이나 행동방식 에 있어서 유의한 차이는 없었다. ${ }^{3}$ 또한, 렘수면행동장애에서 도 실제로는 손으로 물건 잡기, 말하기, 춤추기 등의 비공격 적인 동작들도 $18 \%$ 에서 관찰될 정도로 흔하며, ${ }^{9}$ 단지 폭력적 이거나 과격한 동작들에 비해 보호자들에게 덜 관찰되었을 가능성도 많다. 따라서 수면 중 행동 양상 자체는 렘수면행동 장애와 폐쇄수면무호흡증의 감별진단에 큰 도움은 되지 않 는다고 볼 수 있다. 특히 렘수면행동장애와 폐쇄수면무호흡 을 같이 동반하고 있는 환자의 경우도 있으므로 좀 더 주의를 요하며,$^{10}$ 수면다원검사를 시행하여 무호흡과 이상 행동의 양 상을 확인할 필요가 있다. 수면다원검사 결과뿐만 아니라 지 속기도양압을 시행하였을 때의 반응도 차이가 있다. 폐쇄수 면무호흡으로 인한 가성증상이라면 지속기도양압으로 미세 각성이 줄고 산소포화도가 올라갈 경우 깊은 수면을 취하면 서 증상이 사라지지만, 렘수면행동장애의 경우엔 각성이 줄 면서 렘수면 기간이 길어지게 되면 오히려 행동 증상이 빈번 하게 관찰될 수 있기 때문이다.

렘수면행동장애의 진단은 병력이 매우 중요하므로 환자가 경제적 혹은 기타 여러 가지 이유로 수면다원검사를 받지 못 하면 병력에 의존하여 진단하고 처방을 내리는 경우가 있다. 주로 처방되는 클로나제팜은 호흡과 관련된 근육을 더욱 이 완시키기 때문에 환자가 심한 폐쇄수면무호흡을 가지고 있 다면 오히려 증상을 악화시킬 수 있다. 따라서, 렘수면행동장 애가 의심될 때, 특히 비만, 작은 턱, 짧은 목 등 폐쇄수면무 호흡의 위험인자를 가지고 있는 환자의 경우엔 반드시 수면 다원검사를 시행하여 이상증상이 나타나는 수면 단계가 무 엇인지, 렘수면에서 턱근긴장도의 증가가 나타나는지, 심한 폐쇄수면무호흡을 동반하는지 등을 확인하여 가성렘수면행 동장애와 감별하는 것이 필요하다.

\section{Acknowledgments}

이 연구는 2014년도 양산부산대학교병원 임상연구비 지원으로 이루 어졌음.

\section{REFERENCES}

1. Schenck CH, Mahowald MW. REM sleep behavior disorder: clinical, developmental, and neuroscience perspectives 16 years after its formal identification in SLEEP. Sleep 2002;25:120-138.

2. Nalamalapu U, Goldberg R, DiPhillipo M, Fry JM. Behaviors simulating REM behavior disorder in patients with severe obstructive sleep apnea. Sleep Res 1996;25:311.

3. Iranzo A, Santamaría J. Severe obstructive sleep apnea/hypopnea 
mimicking REM sleep behavior disorder. Sleep 2005;28:203-206.

4. Brunton LL, Chabner BA, Knollmann BC. Goodman \& Gilman's The Pharmacological Basis of Therapeutics. New York: McGraw-Hill, 2011; 314.

5. Foulkes D, Schmidt M. Temporal sequence and unit composition in dream reports from different stages of sleep. Sleep 1983;6:265-280.

6. Yun $\mathrm{CH}$, Ji KH, Ha CK. Melatonin therapy for REM sleep behavior disorder with co-existing moderate-to-severe sleep apnea. J Korean Neurol Assoc 2007;25:187-193.

7. Chen MC, Yu H, Huang ZL, Lu J. Rapid eye movement sleep behavior disorder. Curr Opin Neurobiol 2013;23:793-798.
8. American Academy of Sleep Medicine. International Classification of Sleep Disorders. 3rd ed. Darien, IL: American Academy of Sleep Medicine, 2014.

9. Oudiette D, De Cock VC, Lavault S, Leu S, Vidailhet M, Arnulf I. Nonviolent elaborate behaviors may also occur in REM sleep behavior disorder. Neurology 2009;72:551-557.

10. Jang HJ, Kim B, Ryu HS, Lee GH, Lee SA. Two cases of REM sleep behavior disorder combined with severe obstructive sleep apnea: misdiagnosed as "pseudo-REM sleep behavior disorder" by diagnostic polysomnography. J Korean Sleep Res Soc 2013;10:62-65. 